\title{
Prevalence and clinical correlates of pathological affective display in Alzheimer's disease
}

\author{
Sergio E Starkstein, Ricardo Migliorelli, Alejandra Tesón, Gustavo Petracca, \\ Erán Chemerinsky, Facundo Manes, Ramón Leiguarda
}

\begin{abstract}
This study examined the prevalence and correlates of pathological affect in Alzheimer's disease. A consecutive series of 103 patients with Alzheimer's disease were examined with a comprehensive psychiatric assessment that included the pathological laughing and crying scale (PLACS). Forty patients (39\%) showed pathological affect: $25 \%$ showed crying episodes, and $14 \%$ showed laughing or mixed (laughing and crying) episodes. Patients with pathological affect crying showed significantly higher depression scores and a significantly higher frequency of major depression and dysthymia than patients with no pathological affect. Patients with mixed pathological affect showed significantly more subcortical atrophy on CT than patients with pathological affect crying. Forty seven per cent of the patients with pathological affect had no congruent mood disorder, and they showed a significantly longer duration of illness and more severe anosognosia than patients with pathological affect that was congruent with an underlying mood disorder. The study validates the PLACS, and shows the high prevalence of pathological affect in Alzheimer's disease.
\end{abstract}

(F Neurol Neurosurg Psychiatry 1995;59:55-60)

\author{
Department of \\ Neuropsychiatry and \\ Behavioural \\ Neurology \\ S E Starkstein \\ R Migliorelli \\ A Tesón \\ G Petracca \\ E Chemerinsky \\ F Manes \\ $R$ Leiguarda \\ Department of \\ Clinical Neurology, \\ Raúl Carrea Institute \\ of Neurological \\ Research, Buenos \\ Aires, Argentina \\ S E Starkstein \\ R Leiguarda \\ Correspondence to: \\ Dr Sergio E Starkstein, Raúl \\ Carrea Institute of \\ Neurological Research \\ Montañeses 2325, 1428 \\ Buenos Aires, Argentina. \\ Received 25 October 1994 \\ and in revised form \\ 13 February 1994 \\ Accepted 20 February 1994
}

Keywords: prevalence; pathological affective display; Alzheimer's disease

Abnormalities of facial expression have been variably termed pathological laughing and crying, emotional lability, pseudobulbar affect, and organic emotionality. Poeck ${ }^{1}$ defined emotional lability as the sudden onset of laughing or crying, which the patient is unable to suppress, and which generally occurs in appropriate situations. Poeck also added that emotional lability is always accompanied by an alteration of mood. On the other hand, pathological laughing or crying was defined as the presence of sudden laughing or crying episodes that do not correspond to an underlying emotional change. ${ }^{1}$

Whereas both pathological laughing and crying and emotional lability have been reported in patients with focal brain lesions ${ }^{2}$ or neurological degenerative disorders, ${ }^{1}$ empirical prospective studies in patients with Alzheimer's disease are lacking. Thus the prevalence, clinical correlates, and mechanism(s) of pathological affect in Alzheimer's disease still remain to be examined.

For the present study we tested a consecutive series of 103 patients with Alzheimer's disease with a structured assessment for pathological laughing and crying-namely, the pathological laughing and crying scale (PLACS). We determined the prevalence of both pathological laughing and crying and emotional lability, and examined the presence of relevant demographic, psychiatric, neurological, neuropsychological, and neuroradiological correlates.

\section{Patients and methods \\ PATIENTS}

A consecutive series of 103 patients who met the NINCDS-ADRDA criteria for probable Alzheimer's disease and had a Hachinski ischaemic score $\leqslant 4^{4}$ comprised the study population.

\section{PSYCHIATRIC EXAMINATION}

After informed consent, patients were assessed with the following tests:

Structured clinical interview for DSM-III-R (SCID) $)^{5}$

The SCID is a semistructured diagnostic interview used to assess the major axis I DSM-III-R ${ }^{6}$ disorders. The SCID was given by a psychiatrist blind to the remaining clinical data, and the interview was carried out with the patient and at least one first degree relative. Based on the SCID responses, DSMIII-R axis I diagnoses were made.

\section{Hamilton depression scale (HAM-D)}

The HAM-D is a 17 item interviewer rated scale that measures psychological and autonomic symptoms of depression.

\section{Hamilton anxiety scale $(H A M-A)^{8}$}

The HAM-A is an 11 item interviewer rated scale that measures the severity of generalised or persistent anxiety.

\section{Bech mania scale ${ }^{9}$}

The Bech mania scale assesses the presence and severity of manic symptoms.

\section{Pathological laughing and crying scale} (PLACS) ${ }^{2}$

The PLACS is an interviewer rated scale that quantifies aspects of pathological affect, including the duration of the episodes, their relation to external events, degree of voluntary 
control, inappropriateness in relation to emotions, and degree of resultant distress. Both the reliability and validity of this scale have been previously established. ${ }^{2}$ The scale is given to the patient and at least one first degree relative or caretaker in close contact with the patient. The scale consists of 16 items (eight assessing pathological laughter (PLACS-L) and eight assessing pathological crying (PLACS-C)), which are scored from 0 to 3 points.

\section{Diagnosis of pathological affect}

Following Poeck's diagnostic scheme, ${ }^{1}$ emotional lability was defined as the presence of sudden episodes of laughing or crying in the presence of a congruent mood disorder (for example, episodes of sudden crying in the presence of major depression or dysthymia); pathological laughing and crying was defined as the presence of sudden episodes of laughing or crying in either the absence of a mood disorder, or the presence of a non-congruent mood disorder (for example, pathological laughing in the presence of a major depression). The generic term "pathological affect" was used to refer to the presence of either pathological laughing and crying or emotional lability. Based on these definitions and a clinical assessment (for example, was emotional lability displayed during the interview? Did it occur several times daily? Did it seem excessive in relation to the precipitant?) a diagnosis of pathological affect crying, laughing, or mixed type was made by a neurologist blind to the psychiatric data.

\section{Functional independence measure ${ }^{10}$ \\ The functional independence measure assesses self care, sphincter control, mobility, locomotion, communication, and social cog- nition on a low level scale. Higher scores indi- cate less impairments in activities of daily living.}

\section{Social ties checklist ${ }^{11}$}

The social ties checklist is a 10 item scale that assesses the quantity and quality of social supports. Scores range from 0 to 10 , and higher scores indicate better social supports.

\section{Mini mental state exam (MMSE) 12}

The MMSE is an 11 item examination that has been found to be reliable and valid in assessing a limited range of cognitive functions.

\section{Anosognosia questionnaire-dementia ${ }^{13}$}

The AQ-D consists of 30 questions divided into two sections. The first section assesses intellectual functioning, and the second section examines changes in interests and personality. Each answer is rated as never (0 points), sometimes (1 point), usually (2 points), and always present ( 3 points). Thus higher scores indicate more severe impairments. Form $\mathrm{A}$ is answered by the patient alone (with clarifications by the examiner if needed), whereas form B (a similar questionnaire written in the third person) is answered by the patient's caretaker blind to the patient's answers in form A. The final score is the subtraction between scores in forms $B$ and A. Thus positive scores indicate that the caretaker rated the patient as more impaired than the patient's own evaluation (the patient was less aware of his or her cognitive and emotional deficits).

\section{NEUROLOGICAL EXAMINATION}

Patients were examined with the unified Parkinson's disease rating scale (UPDRS), ${ }^{14}$ a semistructured scale that assesses voice, facial immobility, resting tremor, rigidity (neck and limbs), bradykinesia and hypokinesia, posture, and gait abnormalities. The UPDRS was scored by a neurologist blind to the psychiatric and radiological findings.

\section{NEUROPSYCHOLOGICAL EXAMINATION}

Patients received a comprehensive neuropsychological evaluation that consisted of the following tasks:

\section{Buschke selective reminding test ${ }^{15}$}

This test measures verbal learning and memory during a multiple trial list learning task. The patient listens to a list of words and has to recall as many words as possible. Each subsequent learning trial involves the selective preservation of only those words that were not recalled on the immediately preceding trial. The outcome measures were the long term retrieval (LTR) and the delayed recall.

\section{Benton visual retention test ${ }^{16}$}

This test assesses visual memory and visual perception. Patients are exposed to geometric designs for 10 seconds, and are immediately presented with a card containing the correct design among three different foils. The patient has to select the correct one.

Apraxia subtest of the western aphasia battery ${ }^{17}$ This test assesses the presence and severity of ideomotor apraxia.

\section{Block design ${ }^{18}$}

The block design test examines the presence of constructional apraxia. Patients are presented with red and white blocks and are asked to construct replicas of printed designs.

\section{Digit span ${ }^{18}$}

The digit span test examines auditory attention and consists of two parts. Both consist of seven pairs of random number sequences that the examiner presents at the rate of one per second. In the first part (digits forward) the patient is asked to repeat a string of numbers exactly as it is given, and in the second (digits backwards) the patient is asked to repeat a string of numbers in reverse order.

\section{Wisconsin card sorting test ${ }^{19}$}

This test measures the ability to develop new concepts and shift sets, and also requires the subjects to suppress a previously correct response and produce a new one. Assessment of the overall proficiency of the test was 
judged by the number of categories achieved (maximum 6).

\section{Trail making test ${ }^{20}$}

This test examines visual, conceptual, and visuomotor tracking. The patient is instructed to draw lines to connect consecutively numbered circles on a paper (part A), and then connect the same number of consecutively numbered and lettered circles on another paper by alternating between the two sequences (part B). The patient is urged to connect the circles as quickly as possible to control for graphomotor speed and visual scanning. The trial score is the time to complete part A minus the time to complete part B.

\section{Oral word controlled association test ${ }^{21}$}

This test examines access to semantic information with time constraint. Patients were instructed to name as many words beginning with the letter $F$ as they could in one minute. People's names and proper nouns were not permitted. The letters $A$ and $S$ were then presented successively, one minute being allowed for each letter. The score was the number of words produced in one minute.

\section{Boston naming test ${ }^{22}$}

This test measures the ability to name pictured objects. Line drawings of high and low frequency objects are presented one at a time on cards, which the patient has to name.

\section{Token test ${ }^{23}$}

This test measures verbal comprehension of commands of increasing complexity.

\section{Raven's progressive matrices ${ }^{24}$}

This test measures reasoning in the visual modality. Patients are presented with a pattern problem with one part removed and several pictured inserts, one of which contains the correct pattern. The patient has to select the missing piece to complete the pattern

\section{NEURORADIOLOGICAL EXAMINATION}

Computed tomography was carried out on most of the patients within one week of the clinical evaluation (CT could not be done on

Table 1 Demographic and neurological findings

\begin{tabular}{|c|c|c|c|}
\hline & \multicolumn{3}{|c|}{ Alzheimer's disease } \\
\hline & $\begin{array}{l}\text { No pathological } \\
\text { affect }\end{array}$ & $\begin{array}{l}\text { Pathological } \\
\text { crying }\end{array}$ & $\begin{array}{l}\text { Pathological } \\
\text { mixed }\end{array}$ \\
\hline $\begin{array}{l}\text { No of patients } \\
\text { Age } \\
\text { Sex (\% women) } \\
\text { Education }(y) \\
\text { Duration of illness }(y) \star \star \\
\text { Dementia severity: }\end{array}$ & $\begin{array}{l}63 \\
74 \cdot 4(7 \cdot 7) \\
76(48) \\
10 \cdot 0(4 \cdot 6) \\
4 \cdot 2(2 \cdot 2)\end{array}$ & $\begin{array}{l}26 \\
72 \cdot 5(7 \cdot 1) \\
77(20) \\
8 \cdot 5(5 \cdot 8) \\
3 \cdot 8(2 \cdot 2)\end{array}$ & $\begin{array}{l}14 \\
72 \cdot 0(7 \cdot 7) \\
57(8) \\
12 \cdot 3(4 \cdot 5) \\
6 \cdot 5(3 \cdot 4)\end{array}$ \\
\hline $\begin{array}{l}\text { Mild } \\
\text { Moderate } \\
\text { Severe } \\
\text { Resting tremor } \\
\text { Rigidity } \\
\text { Body bradykinesia } \\
\text { Posture } \\
\text { Gait }\end{array}$ & $\begin{array}{l}48(30) \\
44(28) \\
8(5) \\
0.32(0.6) \\
0.45(0.8) \\
0.86(1.1) \\
0.63(0.9) \\
0.56(0.9)\end{array}$ & $\begin{array}{l}35(9) \\
42(11) \\
23(6) \\
0.36(0.6) \\
0.63(0.8) \\
0.84(1 \cdot 1) \\
0.68(1 \cdot 0) \\
0.57(0.8)\end{array}$ & $\begin{array}{l}29(4) \\
50(7) \\
21(3) \\
0 \cdot 10(0 \cdot 3) \\
0 \cdot 50(0 \cdot 7) \\
0 \cdot 60(1 \cdot 0) \\
0.90(1 \cdot 1) \\
0.30(0 \cdot 6)\end{array}$ \\
\hline
\end{tabular}

Values are means (SD)
13 patients due to scheduling problems). After informed consent, all CT was carried out on a General Electric 8800 CT scanner. Scans were obtained parallel to the orbitomeatal line, with a slice thickness of $5 \mathrm{~mm}$. The slices were digitised with IMAGE software (National Institutes of Health, Bethesda, $\mathrm{MD}$ ), and area measurements were carried out on a Quadra 700 computer (Apple Computers, Cupertino, CA) using the Digital Imaging Processing System software (Hayden Image Processing Group, Madison, WN). The following measurements were made ${ }^{2526}$ :

Sylvian cistern ratio

This is the area of the sylvian cistern (left or right) at the level of the pineal gland, divided by the whole brain area, $\times 100$.

\section{Frontal horn ratio}

This is the area of the frontal horn (left or right) at the level of the foramen of Monro divided by the area of the whole brain at the same level, $\times 100$.

\section{Ventricle brain ratio}

This is the area of the lateral ventricle (left or right) at the waist level over the whole brain area at the same level, $\times 100$.

\section{Temporal horn ratio}

This is the area of the temporal horn (left or right) at the level of the suprasellar cistern, divided by the brain area at the level of the pineal gland, $\times 100$.

\section{Cortical sulci ratio}

This is the sum of the area of the four widest sulci divided by the brain area at the level of the pineal gland, $\times 100$.

\section{STATISTICAL ANALYSIS}

Statistical analysis was carried out on means and SDs, by one way and multivariate analyses of variance (ANOVA, MANOVA) and Tukey post hoc tests. Frequency distributions were analysed with contingency tables. All P values are two tailed.

\section{Results}

Based on the clinical assessment for pathological affect, 26 patients $(25 \%)$ showed pathological affect crying, 14 patients (14\%) showed pathological affect laughing or mixed, and 63 patients $(61 \%)$ showed no pathological affect.

\section{DEMOGRAPHIC FINDINGS (TABLE 1)}

No significant between group differences were found in age, sex, education, and severity of dementia. Patients with mixed pathological affect, however, had a significantly longer duration of illness $(F(2,100)=5.95, \quad \mathrm{P}<$ 0.05).

NEUROLOGICAL FINDINGS (TABLE 1) A two way ANOVA with repeated measures (factor 1: group, repeated measure: UPDRS scores) showed no significant group effect 
$(F(2,100)=2 \cdot 67, \mathrm{NS})$, and no significant group $\times$ UPDRS item interaction $(F=1.05$, NS). Thus, all three groups of patients with Alzheimer's disease had a similar severity of extrapyramidal signs.

Table 2 Psychiatric findings

\begin{tabular}{|c|c|c|c|}
\hline & \multicolumn{3}{|c|}{ Alzheimer's disease } \\
\hline & $\begin{array}{l}\text { No pathological } \\
\text { affect }\end{array}$ & $\begin{array}{l}\text { Pathological } \\
\text { crying }\end{array}$ & $\begin{array}{l}\text { Pathological } \\
\text { mixed }\end{array}$ \\
\hline $\begin{array}{l}\text { Major depression (\% patients) })^{\star \star} \\
\text { Dysthymia (\% patients) } \\
\text { No depression (\% positive) } \\
\text { Hamilton depression scale }{ }^{\star \star} \\
\text { Hamilton anxiety scale (score) } \\
\text { Bech mania scale (score) } \\
\text { Functional independence measure (mean) } \\
\text { PLACS-laughing (score) }{ }^{\star \star} \\
\text { PLACS-crying (score) } \\
\text { Social ties checklist (score) }\end{array}$ & $\begin{array}{l}16(10) \\
24(15) \\
60(38) \\
8 \cdot 7(7 \cdot 1) \\
8 \cdot 4(7 \cdot 7) \\
1 \cdot 0(3 \cdot 1) \\
63 \cdot 0(9 \cdot 9) \\
0 \cdot 0 \\
1 \cdot 8(2 \cdot 6) \\
3 \cdot 5(1 \cdot 6)\end{array}$ & $\begin{array}{l}43(11) \\
38(10) \\
19(5) \\
16 \cdot 5(8 \cdot 3) \\
14 \cdot 3(7 \cdot 5) \\
1.1(2 \cdot 0) \\
63 \cdot 3(6 \cdot 8) \\
0.0 \\
11.9(2 \cdot 9) \\
4 \cdot 5(1 \cdot 6)\end{array}$ & $\begin{array}{l}21(3) \\
29(4) \\
50(7) \\
8 \cdot 6(4 \cdot 7) \\
11 \cdot 2(9 \cdot 0) \\
2 \cdot 6(8 \cdot 5) \\
59 \cdot 2(10 \cdot 1) \\
1 \cdot 8(4 \cdot 6) \\
7 \cdot 3(7 \cdot 1) \\
3 \cdot 8(1 \cdot 8)\end{array}$ \\
\hline
\end{tabular}

Table 3 Neuropsychological findings

\begin{tabular}{|c|c|c|c|}
\hline & \multicolumn{3}{|c|}{ Alzheimer's disease } \\
\hline & $\begin{array}{l}\text { No pathological } \\
\text { affect }\end{array}$ & $\begin{array}{l}\text { Pathological } \\
\text { crying }\end{array}$ & $\begin{array}{l}\text { Pathological } \\
\text { mixed }\end{array}$ \\
\hline \multicolumn{4}{|l|}{ Buschke SRT: } \\
\hline Long term storage & $25 \cdot 5(21 \cdot 0)$ & $21.6(14.9)$ & $16 \cdot 3(18 \cdot 1)$ \\
\hline Delayed recall & $2 \cdot 1(2 \cdot 7)$ & $1.5(1.6)$ & $1 \cdot 2(2 \cdot 2)$ \\
\hline Benton visual retention test & $4 \cdot 2(2 \cdot 4)$ & $4 \cdot 3(2 \cdot 5)$ & $3.9(2.8)$ \\
\hline Token test & $16 \cdot 7(7 \cdot 4)$ & $16 \cdot 7(7 \cdot 5)$ & $13.8(10 \cdot 5)$ \\
\hline Boston naming test & $12 \cdot 7(5 \cdot 2)$ & $12 \cdot 8(4 \cdot 8)$ & $10 \cdot 7(6 \cdot 2)$ \\
\hline Wisconsin card sorting test: categories & $1.7(1 \cdot 8)$ & $1 \cdot 6(2 \cdot 2)$ & $1.9(2 \cdot 1)$ \\
\hline Controlled oral word association test & $28.5(9 \cdot 5)$ & $25.5(11 \cdot 4)$ & $24 \cdot 2(9 \cdot 0)$ \\
\hline Raven's progressive matrices: percentile & $35 \cdot 1(29 \cdot 9)$ & $33.1(35.9)$ & $30 \cdot 3(29 \cdot 7)$ \\
\hline Digits forward & $5 \cdot 0(1 \cdot 2)$ & $4 \cdot 6(1 \cdot 4)$ & $5 \cdot 0(1 \cdot 2)$ \\
\hline Digits backward & $3 \cdot 1(1 \cdot 1)$ & $3.0(1.3)$ & $3.5(1.2)$ \\
\hline Block design & $2 \cdot 7(2 \cdot 4)$ & $2 \cdot 4(2 \cdot 4)$ & $2 \cdot 6(2 \cdot 6)$ \\
\hline Analogies (WAIS) & $8.8(6.8)$ & $9 \cdot 1(7 \cdot 9)$ & $6 \cdot 8(7 \cdot 3)$ \\
\hline Mini mental state exam & $19.6(5.9)$ & $18.0(6.4)$ & $16 \cdot 3(8 \cdot 9)$ \\
\hline
\end{tabular}

Values are means (SD).

Table 4 Neuroradiological findings

\begin{tabular}{|c|c|c|c|}
\hline & \multicolumn{3}{|c|}{ Alzheimer's disease } \\
\hline & $\begin{array}{l}\text { No pathological } \\
\text { affect }\end{array}$ & $\begin{array}{l}\text { Pathological } \\
\text { crying }\end{array}$ & $\begin{array}{l}\text { Pathological } \\
\text { mixed }\end{array}$ \\
\hline $\begin{array}{l}\text { Temporal horn ratio: } \\
\text { Left } \\
\text { Right }\end{array}$ & $\begin{array}{l}31 \cdot 1(41 \cdot 8) \\
33 \cdot 2(36 \cdot 7)\end{array}$ & $\begin{array}{l}25 \cdot 2(32 \cdot 1) \\
22 \cdot 9(18 \cdot 4)\end{array}$ & $\begin{array}{l}43 \cdot 1(39 \cdot 7) \\
35 \cdot 5(37 \cdot 5)\end{array}$ \\
\hline $\begin{array}{l}\text { Sylvian cistern ratio: } \\
\text { Left } \\
\text { Right }\end{array}$ & $\begin{array}{l}171.8(86) \\
140.5(74)\end{array}$ & $\begin{array}{l}143.7(86) \\
133.0(69)\end{array}$ & $\begin{array}{l}139 \cdot 8(60) \\
164.9(102)\end{array}$ \\
\hline $\begin{array}{l}\text { Frontal horn ratio: } \\
\text { Left } \\
\text { Right }\end{array}$ & $\begin{array}{l}196.0(58) \\
188.4(63)\end{array}$ & $\begin{array}{l}188.6(59) \\
176.0(57)\end{array}$ & $\begin{array}{l}213.6(79) \\
194.7(75)\end{array}$ \\
\hline $\begin{array}{l}\text { Lateral ventricle ratio: } \\
\text { Left }^{\star \star} \\
\text { Right } \\
\text { Cortical sulci ratio }\end{array}$ & $\begin{array}{c}602 \cdot 6(200) \\
563.4(171) \\
3.9(0.8)\end{array}$ & $\begin{array}{c}560 \cdot 0(193) \\
555 \cdot 2(186) \\
4 \cdot 2(0 \cdot 8)\end{array}$ & $\begin{array}{c}681.0(234) \\
589.9(182) \\
3.8(0.7)\end{array}$ \\
\hline
\end{tabular}

Results are means (SD)

$\star \star P<0 \cdot 01$.

Table 5 Pathological crying and laughing and emotional lability

\begin{tabular}{lll}
\hline & $\begin{array}{l}\text { Emotional } \\
\text { lability }\end{array}$ & $\begin{array}{l}\text { Pathological } \\
\text { crying-laughing }\end{array}$ \\
\hline No of patients & 21 & 19 \\
Age (y) & $71 \cdot 3(6 \cdot 7)$ & $73 \cdot 7(5 \cdot 6)$ \\
Duration of illness (y) & $3 \cdot 5(2 \cdot 0)$ & $6 \cdot 2(2 \cdot 6)$ \\
Dementia severity (\% patients): & $42(9)$ & $21(4)$ \\
$\quad$ Mild & $29(6)$ & $63(12)$ \\
Moderate & $29(6)$ & $16(3)$ \\
Severe & $19 \cdot 0(7 \cdot 2)$ & $7 \cdot 3(3 \cdot 6)$ \\
Hamilton depression scale $^{\star}$ & $15 \cdot 5(7 \cdot 0)$ & $9 \cdot 2(8 \cdot 2)$ \\
Hamilton anxiety scale (score) $^{\star}$ & $8 \cdot 9(18 \cdot 4)$ & $24 \cdot 8(27 \cdot 2)$ \\
\hline
\end{tabular}

Values are means (SD).
$\star P<0.05$.
PSYCHIATRIC FINDINGS (TABLE 2)

A MANOVA for depression, anxiety, mania, activities of daily living, global cognitive functions, and social ties scores showed a significant main effect (Wilks' Lambda $(12,188)=$ $0.71, P=0.001$ ), and between group differences were further analysed with independent one way ANOVAs. There were significant between group differences in HAM-D scores $(F(2,100)=11.4, P=0.0001)$. Patients with pathological affect crying had significantly higher depression scores than patients with either mixed pathological affect $(P<0.001)$, or patients with no pathological affect $(\mathrm{P}<0.0001)$. Moreover, patients with pathological affect crying also showed a significantly higher frequency of major depression and dysthymia than patients with no pathological affect or mixed pathological affect $\left(\chi^{2}=13 \cdot 3\right.$, $\mathrm{df}=4, \mathrm{P}=0.01$ ). There were also significant between group differences in HAM-A scores $(F(2,100)=5.37, P<0.01)$. Patients with pathological affect crying had significantly higher anxiety scores than patients with no pathological affect $(P=0.001)$.

Patients with pathological affect (either crying or mixed) had significantly higher PLACS total scores than patients without pathological affect $(F(2,100)=72 \cdot 1, \mathrm{P}<0.0001)$. Finally, patients with pathological affect crying had significantly higher PLACS-C scores than patients with mixed pathological affect $(P<$ 0.0001 ), whereas patients with mixed pathological affect had significantly higher PLACSL scores than patients with pathological affect crying $(\mathrm{P}<0.0001)$.

NEUROPSYCHOLOGICAL FINDINGS (TABLE 3)

A MANOVA for neuropsychological tests showed no significant main effect (Wilks' Lambda $=0 \cdot 74, \mathrm{df}=28,156 ; \mathrm{NS}$ ). Thus patients with either pathological affect crying, mixed pathological affect, or no pathological affect showed a similar severity and profile of cognitive impairments.

NEURORADIOLOGICAL FINDINGS (TABLE 4)

Computed tomography was carried out in 90 patients. A three way ANOVA with repeated measures (factor 1: group, repeated measures: site and size) showed a significant group $\times$ size $\times$ site interaction $(F(6,261)=3 \cdot 80, \mathrm{P}=$ $0.001)$. Patients with mixed pathological affect had a significantly larger left lateral ventricle than patients with either pathological affect crying, or no pathological affect $(P<$ $0 \cdot 00001)$. Patients with no pathological affect showed a significantly larger left lateral ventricle than patients with pathological affect crying $(P<0.01)$. No significant between group differences were found in measurements of cortical atrophy (table 4).

PATHOLOGICAL LAUGHING AND CRYING, AND EMOTIONAL LABILITY (TABLE 5)

Twenty one of the 40 patients $(53 \%)$ with pathological affect had emotional lability (pathological affect display congruent with the emotional disorder), whereas the remaining 19 patients $(47 \%)$ had pathological laughing or crying. 
Patients with pathological laughing or crying had a significantly longer duration of illness $(F(1,38)=6.78, P<0.05)$, and significantly higher anosognosia scores $(F(1,38)=4.59, \mathrm{P}<0.05)$, whereas patients with emotional lability had significantly higher Hamilton depression $(F(1,38)=27 \cdot 6$, $\mathrm{P}<0.0001)$, and anxiety scores $(F(1,38)=$ $4 \cdot 12, P<0 \cdot 05)$. No other significant between group differences were found in the remaining clinical and neuroradiological variables.

\section{DEPRESSION WITH OR WITHOUT}

\section{PATHOLOGICAL AFFECT}

Twenty five (47\%) of the 53 patients with depression had pathological affect. The frequency of dysthymia and major depression in depressed patients with or without pathological affect was similar (dysthymia $60 \%$ and $50 \%$ respectively, and major depression $40 \%$ and $50 \%$ respectively). Depressed patients with pathological affect had significantly more severe dementia than depressed patients without pathological affect $\left(\chi^{2}=5 \cdot 70, \mathrm{df}=2, \mathrm{P}<\right.$ 0.05 ), but no significant between group differences were found in demographic, neuropsychological, neuroradiological, or psychiatric variables.

\section{Discussion}

This study examined the prevalence and correlates of emotional lability in a consecutive series of 103 patients with Alzheimer's disease, and there were several important findings. Firstly, $39 \%$ of a consecutive series of patients with Alzheimer's disease showed pathological affect. Secondly, patients with pathological affect crying showed significantly higher depression and anxiety scores, and a significantly higher frequency of major depression and dysthymia than patients with no pathological affect. Patients with mixed pathological affect showed significantly more severe subcortical atrophy than patients with pathological affect crying. Thirdly, whereas $53 \%$ of patients with pathological affect had an underlying mood disorder that was congruent with the type of pathological affect display, the remaining $47 \%$ had either no mood disorder, or a mood disorder not congruent with the type of pathological affect display. Finally, about $50 \%$ of the patients with Alzheimer's disease with depression also had pathological affect.

Before further comments, it is necessary to consider some limitations of the study. Clinical criteria for the diagnosis of pathological affect have not been developed, and we diagnosed pathological affect based on a semistructured interview. The finding, however, that patients with pathological affect had significantly higher PLACS scores than patients without pathological affect, and the finding that patients with pathological affect crying had significantly higher PLACS crying scores than patients with mixed pathological affect, provides partial validation of our diagnostic scheme. Whereas pathological affect was associated with more severe dementia, no signifi- cant differences between patients with and without pathological affect were found on neuropsychological tests. This discrepancy may be explained by the fact that the severity of dementia was assessed with the clinical dementia rating, ${ }^{27}$ which not only considers cognitive functioning, but social functioning and activities of daily living as well.

Although pathological affect has often been reported in patients with Alzheimer's disease, ${ }^{1}$ this is, to our knowledge, the first study to examine the prevalence of this disorder with standardised instruments. We found that $39 \%$ of patients with Alzheimer's disease showed pathological affect. Most of them (25\%) showed pathological crying and $14 \%$ showed laughing or mixed (laughing and crying) episodes. The question that now arises is what is the mechanism of pathological affect in Alzheimer's disease? Patients with pathological affect crying showed a significantly higher frequency of major depression and dysthymia, and significantly higher depression and anxiety scores than patients with no pathological affect. Thus the presence of pathological affect crying in Alzheimer's disease may be a marker of an underlying depression. On the other hand, patients with mixed pathological affect showed similar depression, anxiety, and mania scores to patients with Alzheimer's disease without pathological affect, suggesting that mixed pathological affect is not related to an underlying mood disorder. Patients with pathological laughing or crying showed significantly higher anosognosia scores (they were less aware of their cognitive and behavioural problems) than patients with emotional lability. Because anosognosia in Alzheimer's disease may be related to deficits in a self monitoring system related to cognitive functions, ${ }^{28}$ pathological laughing or crying may result from a lack of self monitoring of affective display.

Our study suggests the presence of two types of pathological affect in Alzheimer's disease. The first type is emotional lability (sudden episodes of crying or laughing in the presence of a congruent mood disorder): most patients with pathological affect crying had either dysthymia or major depression. The second type of pathological affect in Alzheimer's disease is pathological laughing or crying (sudden episodes of crying or laughing in the absence of a congruent mood disorder): about half of the patients with pathological affect had either no underlying mood disorder, or an affective disorder that was incongruent with the pathological affective display (for example, pathological affect laughing in the presence of a major depression). Whereas there were significant between group differences in duration of illness and depression, anxiety, and anosognosia scores, future studies should further validate these types of pathological affect.

Ross and Stewart ${ }^{29}$ have recently proposed a mechanism for emotional lability. They hypothesised that depression causes "state changes" in the limbic system so that the threshold for displaying mood congruent 
extreme affective behaviours is lowered. They further suggested that if this lowered threshold is combined with a brain lesion that reduces the neocortical control of limbic behaviours, pathological affect would result. Our study provides partial support for this hypothesis, as almost half of the patients with Alzheimer's disease with depression had pathological affect. There were no significant differences, however, in CT measurements of brain atrophy between depressed patients with Alzheimer's disease with or without pathological affect, suggesting that depression and brain atrophy are not sufficient to produce emotional lability. Moreover, we could not find significant differences between depressed patients with Alzheimer's disease with pathological affect and depressed patients with Alzheimer's disease without pathological affect in terms of demographic, psychiatric, neurological, or neuropsychological variables.

A mechanism for pathological laughing and crying was proposed by Poeck. ${ }^{1}$ A review of the medical literature showed that most patients with pathological laughing and crying had lesions involving the internal capsule and the basal ganglia, the substantia nigra, cerebral peduncles and caudal hypothalamus, and the pyramidal tracts. ${ }^{1}$ Based on these findings, Poeck speculated that pathological laughing and crying may be produced by the interruption of a control system lying at the base of the brain stem, somewhere between the medulla oblongata and the thalamus. In support, Andersen et al have recently reported that patients with severe pathological crying after stroke had large bilateral pontine lesions, and suggested that pathological crying may result from damage to the raphe nuclei in the brainstem or ascending serotonergic projections. ${ }^{30}$ The present study provides partial support for this hypothesis, as patients with mixed pathological affect had significantly more severe subcortical atrophy (at the level of the left lateral ventricle) than patients with Alzheimer's disease with no pathological affect or emotional lability. Another important finding was that patients with pathological crying and laughing had significantly more anosognosia than patients with emotional lability, suggesting that pathological crying and laughing may result from a lack of self monitoring of affective display.

In conclusion, our study showed that pathological affect is a frequent finding among patients with Alzheimer's disease. More studies are required to establish the mechanism of pathological affect in Alzheimer's disease, and to examine whether emotional lability and pathological laughing and crying in patients with Alzheimer's disease show a specific response to treatment with tricyclic antidepressants or dopaminergic agonists.

This study was partially supported by a grant from the Raúl Carrea Institute of Neurological Research and Qualitas Medicina. We thank Dr Robert G Robinson for his valuable suggestions, and Dr Liliana Sabe, Laura Jason, Mariela Juejati, Silvana Dancygier, and Gabriela Kusis for helping with neuropsychological testing.

1 Poeck K. Pathophysiology of emotional disorders associated with brain damage. In: Vinken PJ, Bruyn GW, eds. Handbook of clinical neurology. Amsterdam: North Holland Publishing Co, 1969:343-67.

2 Robinson RG, Parikh RM, Lipsey JR, Starkstein SE, Price TR. Pathological laughing and crying following stroke: validation of measurement scale and double blind treatment study. Am f Psychiatry 1993;150:286-93.

3 McKhann G, Drachman D, Folstein MF, Katzman R, Price D, Stadlan EM. Clinical diagnosis of Alzheimer's disease: report of the NINCDS-ADRDA Work Group under the auspices of the Department of Health and Human Services Task Force on Alzheimer's disease. Neurology 1984;34:939-44.

4 Hachinski VC, Iliff LD, Zilhka L, et al. Cerebral blood flow in dementia. Arch Neurol 1975;40:97-103

5 Spitzer RL, Williams JBW, Gibbon M, First MB. The structured clinical interview for DSM-III-R (SCID). I: history, rationale, and description. Arch Gen Psychiatry 1992;49:624-9.

6 American Psychiatric Press. Diagnostic and statistical manual of mental disorders revised. Washington, DC American Psychiatric Press. 1987.

7 Hamilton MA. A rating scale for depression. $f$ Neurol Neurosurg Psychiatry 1960;23:56-62.

Hamilton MA. The assessment of anxiety states by rating. Br ₹ Med Psychol 1959;32:50-5.

9 Bech P, Kastrup M, Rafaelsen OJ. Mini-compendium of rating scales for states of anxiety, depression, mania, rating scales for states of anxiety, depression, mania, Acta Psychiatr Scand 1986;73(suppl 236):29-31.

10 Granger CV, Hamilton BB, Kayton R. Guide for use of the uniform data set for medical rehabilitation. Buffalo, NY Uniform Data System for Medical Rehabilitation, 1986

11 Starr LB, Robinson RG, Price TR. Reliability, validity and clinical utility of the Social Functioning Exam in the assessment of stroke patients. Exp Aging Res 1983;9: 101-10

12 Folstein MF, Folstein SE, McHugh PR. Mini-mental state: a practical method for grading the cognitive state of patients for the clinician. F Psychiatr Res 1975; 12:189-98.

13 Migliorelli R, Teson A, Sabe L, Petracchi M, Leiguarda R Starkstein SE. Prevalence and correlates of dysthymia and major depression in Alzheimer's disease. $A m \mathcal{F}$ and major depression in

14 Fahn S, Elton E. UPDRS development committee. Unified Parkinson's disease rating scale. In: Fahn S, Marsden CD, Goldstein M, Calne CD, eds. Recen developments in Parkinson's disease. Florham Park, NJ Macmillan, 1987:153-63.

15 Buschke H, Fuld PA. Evaluating storage, retention, and retrieval in disordered memory and learning. Neurolog 1974;24:1019-25.

16 Benton $\mathrm{AL}$. The revised visual retention test, 4th ed. New York: The Psychological Corporation, 1974.

17 Kertesz A. Western aphasia battery. New York: Grune and Stratton, 1982.

18 Wechsler D. Wechsler adult intelligence scale manual. New York: Psychological Corporation, 1955.

19 Nelson HE. A modified card sorting test sensitive to frontal lobe defects. Cortex 1976;12:313-24.

20 Reitan RM. Validity of the trail making test as an indicator of organic brain damage. Percept Mot Skills 1958; 8:271-6.

21 Benton AL. Differential behavioral effects in frontal lobe disease. Neuropsychology 1968;6:53-60.

22 Kaplan EF, Goodglass H, Weintraub S. The Boston naming test. Philadelphia: Lea and Febiger, 1983.

23 De Renzi E, Faglioni P. Development of a shortened version of the token test. Cortex 1978;14:41-9.

24 Raven JC, Court JH, Raven J. Manual for Raven's progressive matrices and vocabulary scales. London: $\mathrm{H} \mathrm{K}$ Lewis and Co Ltd, 1986.

25 Starkstein SE, Robinson RG, Price TR. Comparison of patients with and without post-stroke major depression matched for size and location of lesion. Arch Gen Psychiatry 1988;45:247-52.

26 Starkstein SE, Folstein SE, Brandt J, Pearlson GD, McDonnell A, Folstein M. Brain atrophy in Huntington's disease: a CT-scan study. Neuroradiology 1989;31:156-9.

27 Morris JC. The Clinical Dementia Rating (CDR): current version and scoring rules. Neurology 1993;43:2412-4

28 Michon A, Deweer B, Pillon B, Agid Y, Dubois B Relation of anosognosia to frontal lobe dysfunction in Alzheimer's disease. $\mathcal{F}$ Neurol Neurosurg Psychiatry 1994; 57:805-9.

29 Ross ED, Stewart RS. Pathological display of affect in patients with depression and right frontal brain damage. F Nerv Ment Dis 1987;175:165-72.

30 Andersen G, Ingeman-Nielsen M, Vestergaard K, Riis JO. Pathoanatomic correlations between poststroke pathological crying and damage to brain areas involved in serotonergic neurotransmission. Stroke 1994;25: 